\title{
4 Predicting soil attributes for environmental modelling
}

\author{
Nurhussen M.N. Seid, Birru Yitaferu, Feras \\ Ziadat, Andreas Klik and Wondimu Bayu
}

\section{Introduction}

The UNPRA-Ethiopia project 'Unlocking the potential of rainfed agriculture in Ethiopia for improved rural livelihoods' aims to improve the livelihoods of rural communities in the rainfed agro-ecosystem of the Amhara region of Ethiopia. This can be achieved by improving agricultural productivity and conserving ecosystem resources through integrating affordable and appropriate technologies in a favourable socio-economic environment. One component of the project is to monitor and model the impact of community-based soil and water conservation interventions on land degradation at field and watershed levels. To achieve this, quantitative information and spatial distribution of soil properties are among the main prerequisites. The reliability of land use decisions depends largely on the quality of soil information used to derive them (Bouma, 2001; Mermut and Eswaran, 2001; Salehi et al., 2003). Predictive mapping techniques, such as linear and multiple regression, geostatistics (i.e. kriging and co-kriging), fuzzy logic, neural networks and classification and regression trees have been used to develop soil and natural resource maps (McBratney et al., 2003; Scull et al., 2005).

Ongoing research in digital soil mapping has demonstrated that reasonably accurate soil maps can be produced using quantitative predictive models (Giasson et al., 2006; Stum, 2010). Moreover, much research has provided optimistic results, with some researchers obtaining better results than for traditional soil surveys (Liu et al., 2006; Aksoy et al., 2009; Al-Shamiri and Ziadat, 2012), and numerous complements related to satellite data enriched with topographic information for the mapping of natural resources have been reported (McBratney et al., 2003; Rossiter, 2005; Scull et al., 2005). Such research has been based on the premise of a strong link between landscape pattern and landscape processes, functions and evolution (Phillips, 2002). Soillandscape modelling has also been used to model the spatial distribution of specific soil properties, including A-horizon thickness, organic matter content, extractable phosphorus, $\mathrm{pH}$, sand and silt content (Moore et al., 1993), and A-horizon thickness and solum depth (Gessler et al., 1995). The empirical models developed in these studies explained 41-68 per cent of the variation in 
soil properties using different terrain attributes (Moore et al., 1993; Gessler et al., 1995).

The objectives of this study were to provide an approach for predicting soil attributes based on a digital elevation model (DEM) and remote sensing.

\section{Materials and methods}

The study area is located in the Lake Tana basin in the Gumara-Maksegnit watershed of the Amhara region in Ethiopia, within the latitudes $12^{\circ} 24^{\prime}-12^{\circ} 31^{\prime}$ $\mathrm{N}$ and $37^{\circ} 33^{\prime}-37^{\circ} 37^{\prime} \mathrm{E}$. It is centred $45 \mathrm{~km}$ south-west of Gondar town and covers an area of $56 \mathrm{~km}^{2}$. The area was divided into a number of $500 \mathrm{~m}$ square grids. Soil samples were taken within each grid in the watershed (Figure 4.1). Each site was excavated to a depth $100 \mathrm{~cm}$, or an impeding layer, using an auger. Food and Agriculture Organization of the United Nations (FAO) terminology (FAO, 2006) was used to describe the sampling sites. The soil attributes and site characteristics recorded were Global Positioning System (GPS) coordinates (easting, northing and elevation), soil depth using an auger, slope steepness (per cent) estimated using clinometers, surface stone cover (per cent) and stone content of the topsoil layer $(0-25 \mathrm{~cm})$. A sample of soil for each soil observation was taken for laboratory analysis. The following soil attributes were analysed for each observation: clay, silt, sand, organic matter, total nitrogen and available phosphorus content and $\mathrm{pH}$ and bulk density.

\section{DEM creation and analysis}

The accuracy of three DEMs derived from Shuttle Radar Topography Mission (SRTM) 90-m resolution DEM, Advanced Space-borne Thermal Emission and Reflection Radiometer (ASTER) 30-m and contour derived DEM were compared to select the suitable one for this research. Contour lines of the study area were digitized by the Ethiopian map agency from topographic maps (scale 1:50,000), with 40-m vertical intervals. TOPOGRID algorithm in ArcGIS 9.3 was used to create 30-m resolution DEM. The accuracy of the DEMs was assessed using two methods: visual assessment (visual comparison) after delineating the watershed with the three DEMs, and quantitatively by calculating the root mean square error (RMSE) of the DEMs from 224 elevation spots. The following terrain attributes were derived from the DEM using standard commands in ArcGIS: slope; profile, plan and mean curvatures; aspect; and flow accumulation area. The average upslope contributing area (upslope flow accumulation) was calculated by multiplying the average flow accumulation grid by the area of the pixel (flow accumulation $\times 8,100$ ). The compound topographic index (CTI) for each pixel was also calculated using the formula (Moore et al., 1993): CTI $=\ln ($ As/tan D), where As is the average upslope contributing area and D is the average slope degree. A stream network for the watershed was derived using ArcSWAT software and the watershed was also automatically divided into a number of sub-watersheds (Figure 4.1). Each small 
$74 \quad$ N. Seid et al.

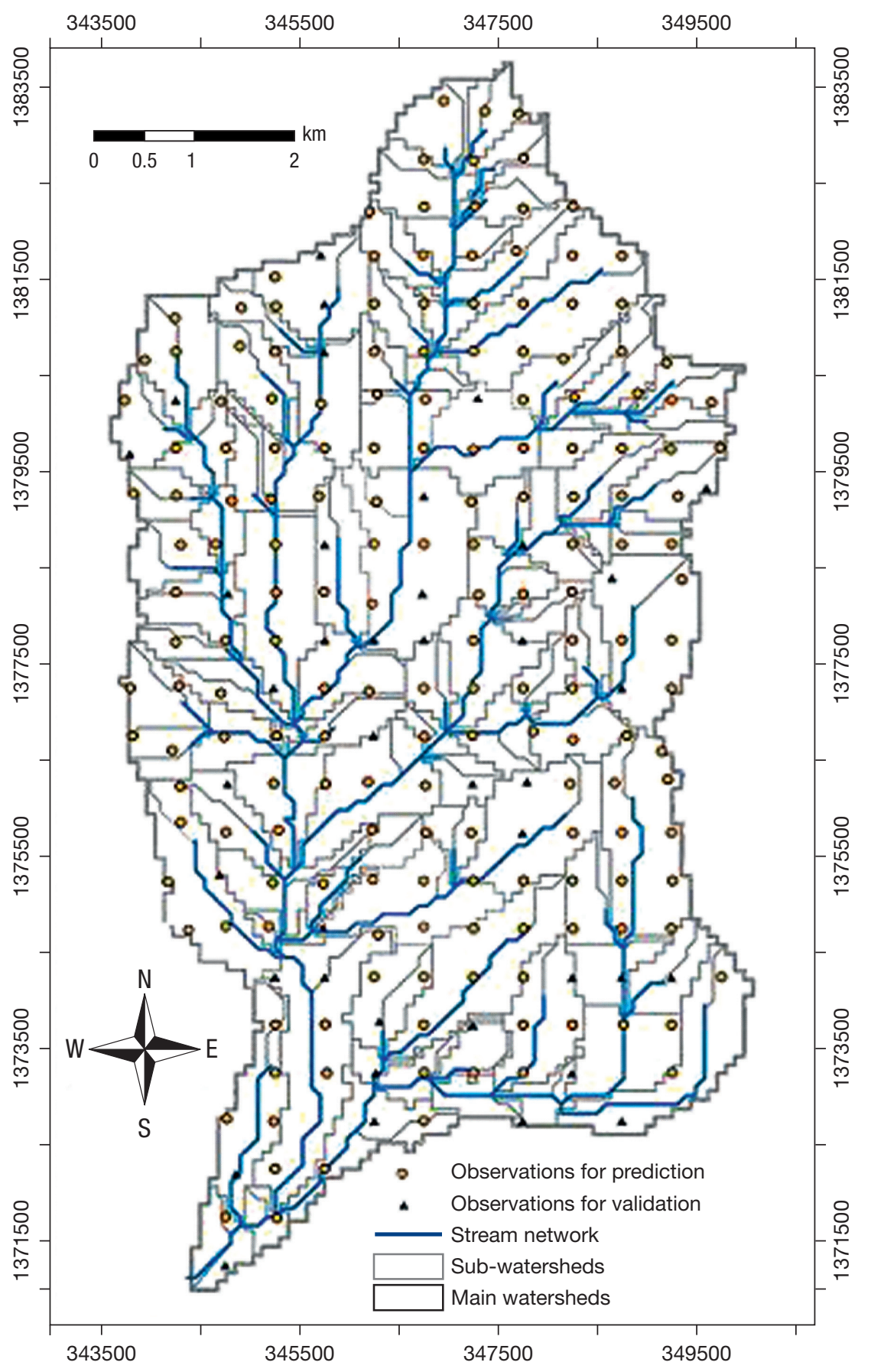

Figure 4.1 Distribution of field observations, watershed boundary, stream network and sub-watershed divisions for the Gumara-Maksegnit watershed 


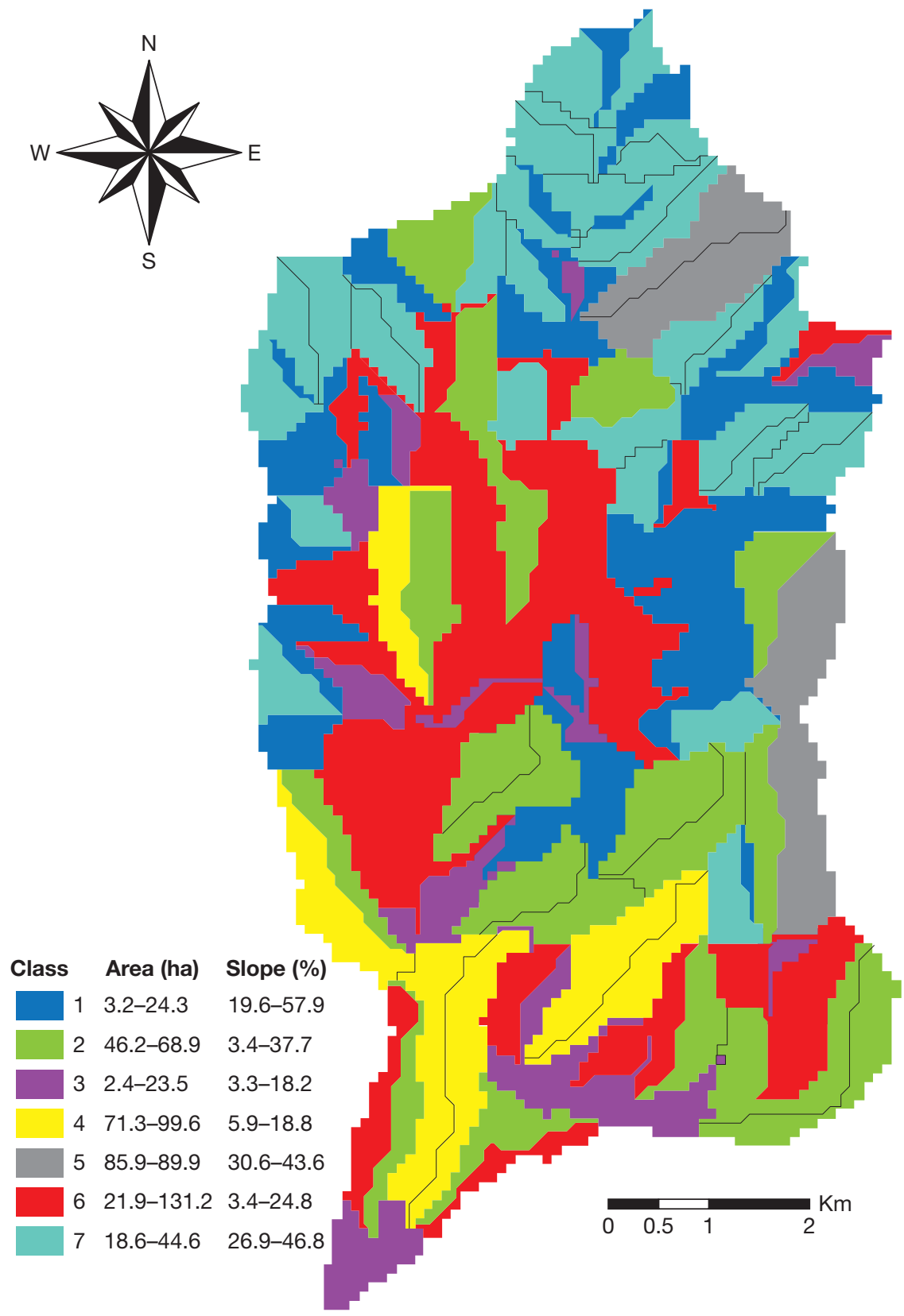

Figure 4.2 Distribution and characteristics of the seven sub-watershed classes 
watershed was subdivided into two facets (subdivisions), which were separated by the streamline passing through with the sub-watersheds (Figure 4.1). The generated facets were classified automatically in ArcGIS into classes (Figure 4.2) based on their characteristics (average area and slope).

To improve the prediction of soil attributes, an ASTER satellite image taken in March 2007 and a SPOT (Satellites Pour l'Observation de la Terre) satellite image taken in October 2007 were used. The images were corrected radiometrically and geometrically using ENVI (Environment for Visualizing Images) software. The images were georeferenced and resampled to the same spatial resolution $(15 \times 15 \mathrm{~m})$ and layer stacked for producing a normalized difference vegetation index (NDVI) map. The NDVI values were calculated for each pixel.

Terrain attributes and NDVI values for each observation were generated for statistical analysis. Statistical analyses were implemented within each class between the derived terrain attributes, NDVI values and collected soil attributes from field observations using Statistical Package for the Social Sciences (SPSS) v.15 software. Multiple linear regression models were usually employed to predict dependent (soil attributes) from independent variables (NDVI and terrain attributes). From a total of 220 observations, 180 were randomly selected for analysis and the remaining forty observations were used to assess the accuracy of the prediction model. Map algebra of ArcGIS was used to get predicted soil attribute grids using statistical analysis results and raster grids for each class (slope per cent, contributing area, CTI, aspect classes, curvature classes, NDVI values of ASTER and SPOT images). Predictions for individual classes were merged together to generate predicted values for the whole watershed. The prediction accuracy was verified by comparing the predicted and measured values using forty randomly selected field observations (Figure 4.1).

\section{Results and discussion}

\section{DEM accuracy}

ASTER DEM, contour derived DEM and SRTM DEM were derived and the SRTM DEM was selected for the study. Qualitative analysis of the DEMs (Figure 4.3) showed that SRTM $90 \mathrm{~m}$ resolution DEM was better than ASTER $30 \mathrm{~m}$ resolution DEM or contour derived $30 \mathrm{~m}$ resolution DEM in representing the area when used to delineate the watershed boundary. Wechsler (2006) states that visualization techniques may be valuable in conveying the implications of potential inaccuracies inherent in DEM data sets, however they are often not accompanied by quantitative results. The RMSE for 224 elevation spots (Table 4.1) is higher (lower accuracy) for contour derived DEM (37.8 $\mathrm{m})$ and lower (higher accuracy) for SRTM derived DEM (26.2 m). This is consistent with several studies where the errors in vertical elevation estimated by DEMs were typically between 0.5 and 1.5 times the pixel size. Furthermore, this indicates high accuracy considering the resolution of the DEM $(90 \mathrm{~m})$. Therefore, SRTM 90 m resolution DEM was selected for this study. 
Table 4.1 Accuracy of digital elevation models for elevation data

\begin{tabular}{llll}
\hline DEM source & $\begin{array}{l}\text { Grid resolution } \\
(\mathrm{m})\end{array}$ & $\begin{array}{l}\text { Number of } \\
\text { observations }\end{array}$ & $\begin{array}{l}\text { RMSE } \\
(\mathrm{m})\end{array}$ \\
\hline ASTER & 30 & 224 & 28.1 \\
Contour & 30 & 224 & 37.8 \\
SRTM & 90 & 224 & 26.2 \\
\hline
\end{tabular}

The RMSE increased (lower accuracy) as the grid cell resolution increased for the study area (Table 4.1). These results contradict findings reported by other researchers (Gao, 1997; Ziadat, 2007). However, these comparisons were made from DEMs of identical source with different resolutions. In this study the comparison was done in DEMs with different sources and resolutions. Many researchers have demonstrated that higher resolution is not necessarily better when it comes to the computation of DEM derived topographic parameters (Wechsler, 2000; Zhou and Liu, 2004). However, selection of an appropriate resolution will depend on characteristics of the study area and the nature of the analysis (Wechsler, 2006). Thompson et al., (2001) and Wechsler (2006) also concluded that higher resolution DEMs may not be necessary for soil landscape modelling.

\section{Soil landscape modelling using regression models to predict soil attributes}

The range of $\mathrm{R}^{2}$ between soil attributes and terrain attributes and NDVI was 0.06-0.85 (Table 4.2). The regression model explained 25 per cent to 76 per cent variation for soil depth, 12 per cent to 80 per cent variation for clay percentage, 21 per cent to 73 per cent variation for silt percentage, 6 per cent to 81 per cent of variation for sand percentage, 18 per cent to 85 per cent of variation for organic matter, 21 per cent to 65 per cent of variation for bulk density, 14 per cent to 79 per cent of variation in $\mathrm{pH}, 9$ per cent to 78 per cent of variation in total nitrogen, 7 per cent to 71 per cent of variation in available phosphorous, 7 per cent to 69 per cent of variation in stone cover on the surface and 13 per cent to 79 per cent of variation for stone on the soil at different classes. $\mathrm{R}^{2}$ depended on the type of soil attribute and the watershed subdivisions for which the relationship was being established. In general, the $\mathrm{R}^{2}$ values were acceptable compared with previous studies (Sumfleth and Duttmann, 2008; Van de Wauw et al., 2008; Kunkel et al., 2011) and were used to generate predictions of the various soil attributes within the seven classes. The regression models established for each class (Table 4.3) were used to derive predicted soil attributes. The predicted values were compared with observed data at forty randomly selected sites.

The RMSE between predicted soil characteristics and those measured in the field (Table 4.4) indicated a good accuracy of prediction using the regression 
$N$. Seid et al.

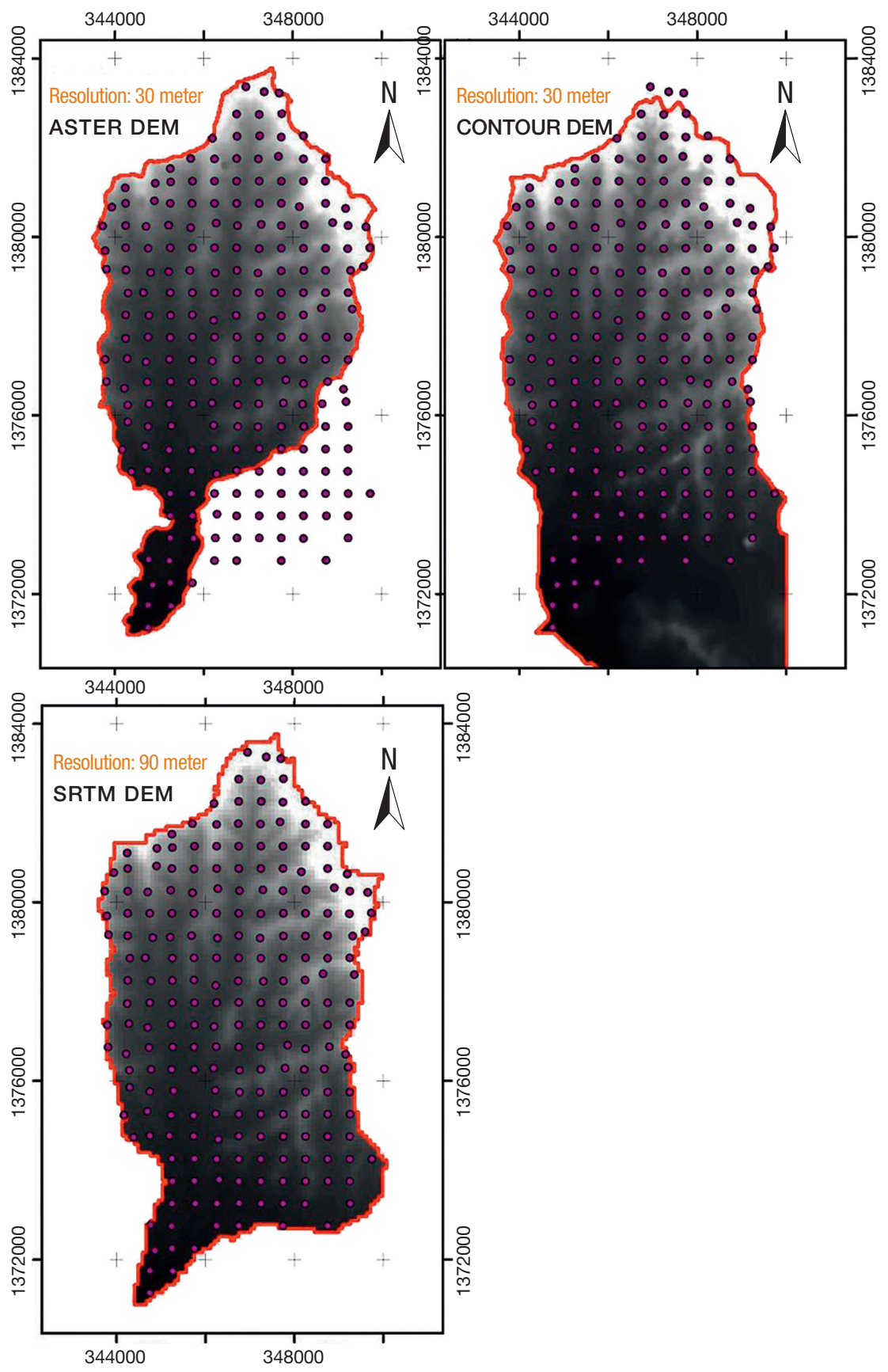

Figure 4.3 Qualitative comparison of the DEMs after delineating the watershed 


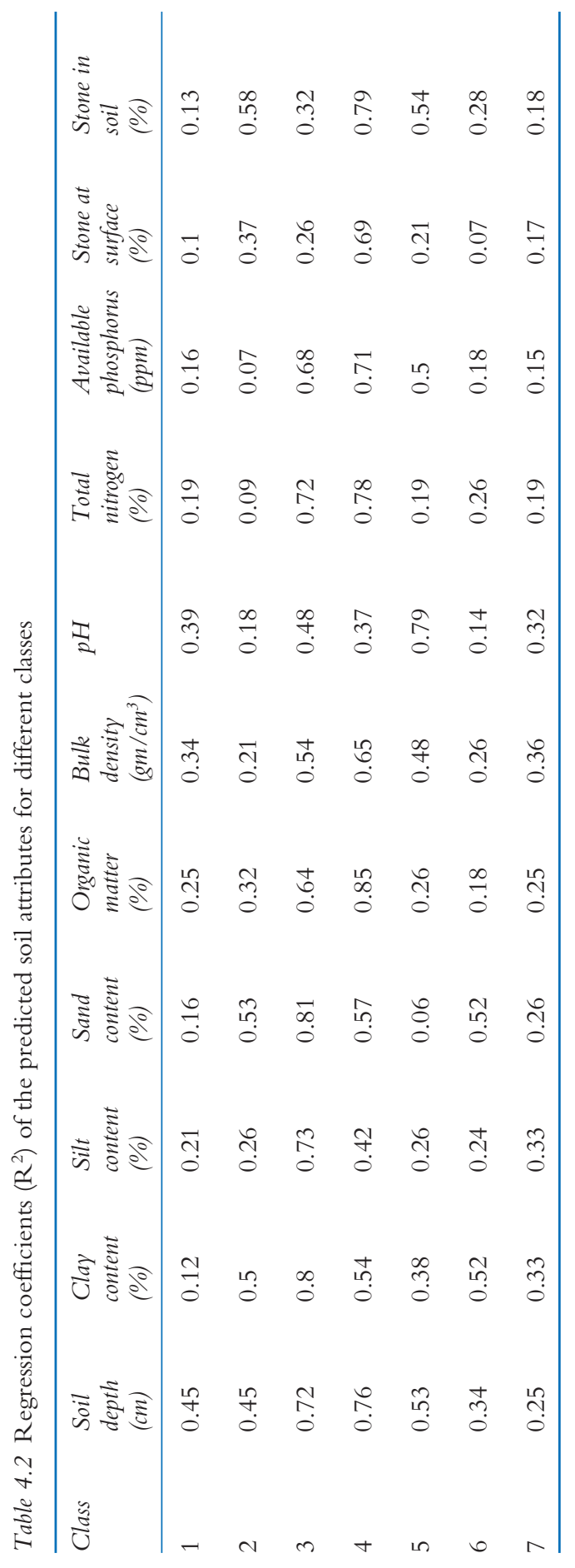




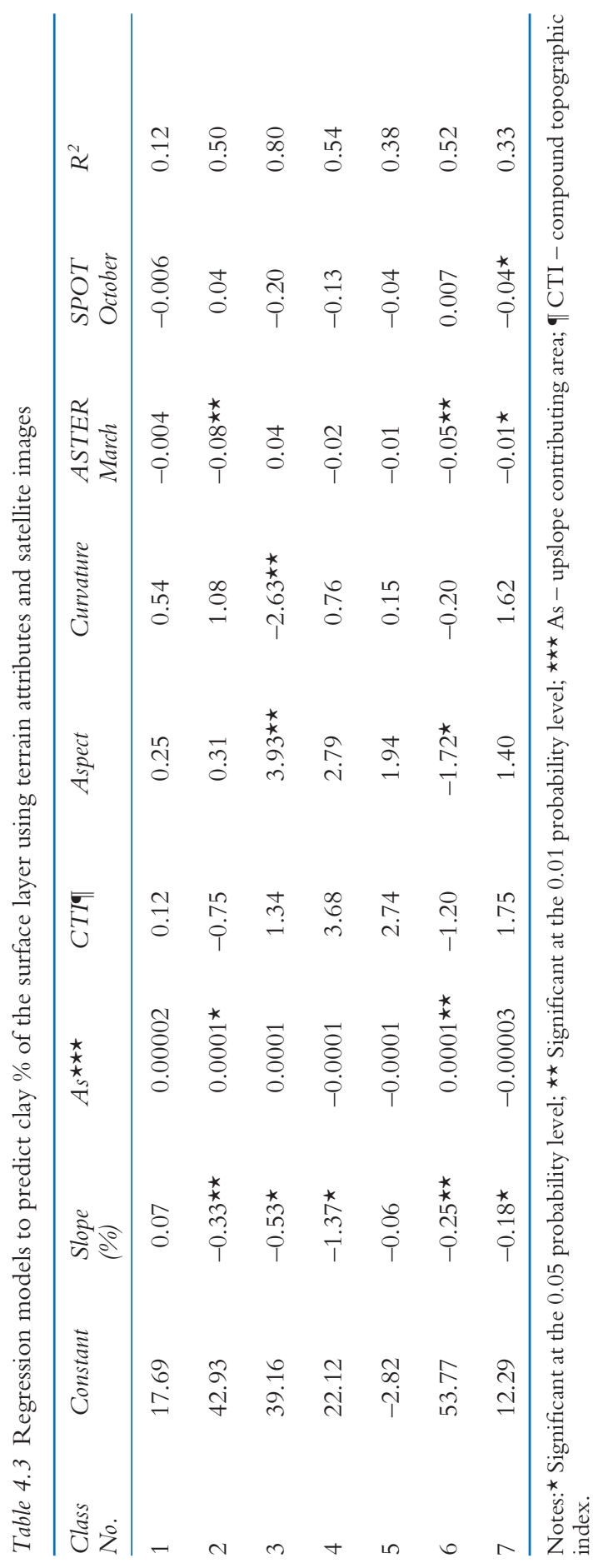


Table 4. 4 Root mean square error between field observations and predicted soil attributes using multiple regression model

\begin{tabular}{lcc}
\hline Predicted soil attributes & 180 observations & 60 observations \\
\hline Soil depth $(\mathrm{cm})$ & 26.4 & 33.7 \\
Clay (\%) & 12.6 & 12.70 \\
Silt (\%) & 7.3 & 8.59 \\
Sand (\%) & 9.4 & 10.24 \\
Organic matter (\%) & 1.39 & 1.55 \\
Bulk density $\left(\mathrm{g} / \mathrm{cm}^{3}\right)$ & 0.18 & 0.24 \\
$\mathrm{pH}$ & 0.38 & 0.46 \\
Total N (\%) & 0.29 & 0.09 \\
Available P (mg/ $\left.\mathrm{kg}^{1}\right)$ & 19.41 & 17.12 \\
Surface stone cover $(\%)$ & 12.2 & 14.15 \\
Stone in the soil $(\%)$ & 12.4 & 17.13 \\
\hline
\end{tabular}
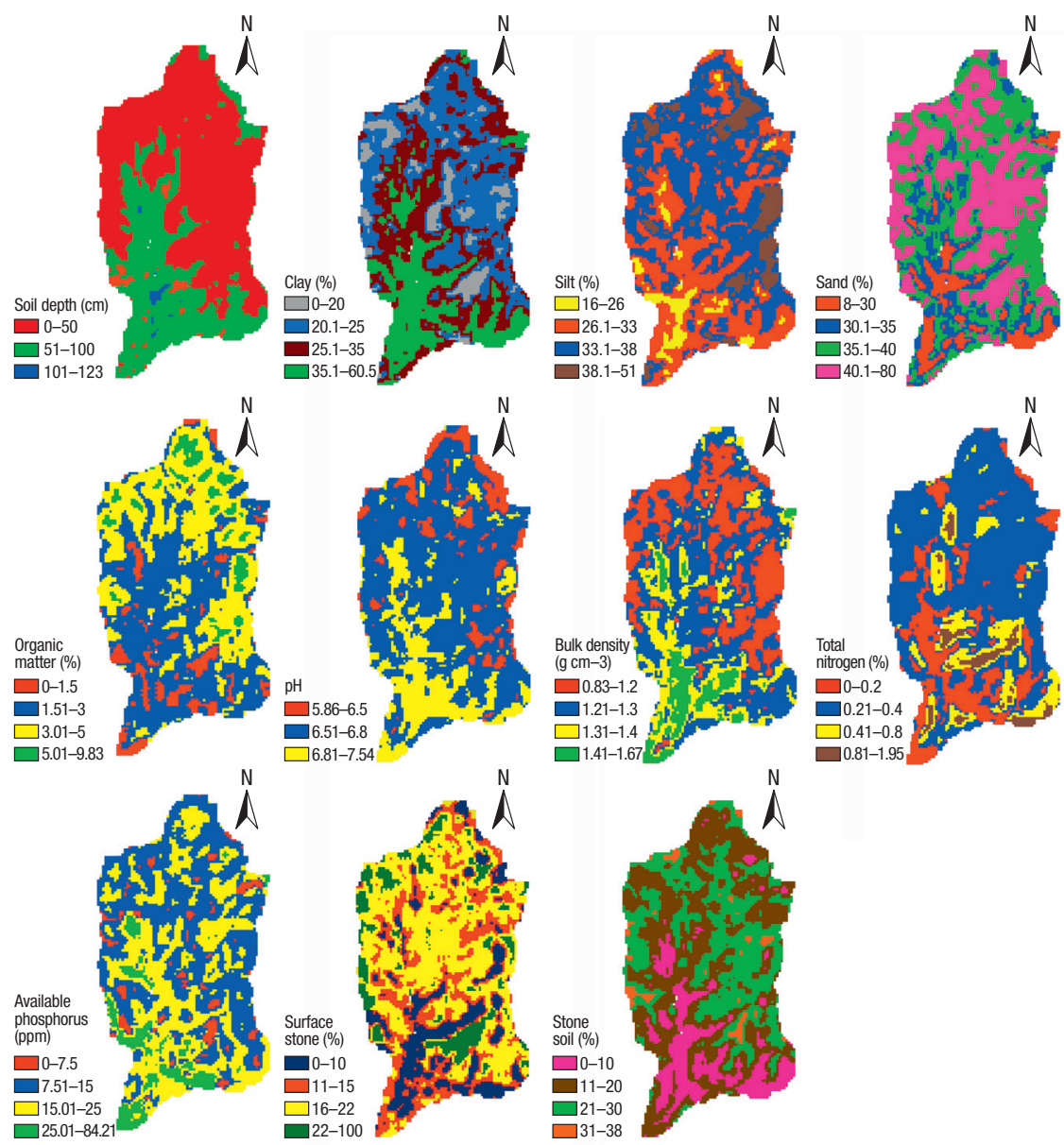

Figure 4.4 Predicted soil attributes of the surface soil using terrain attributes, satellite images and 180 field observations 


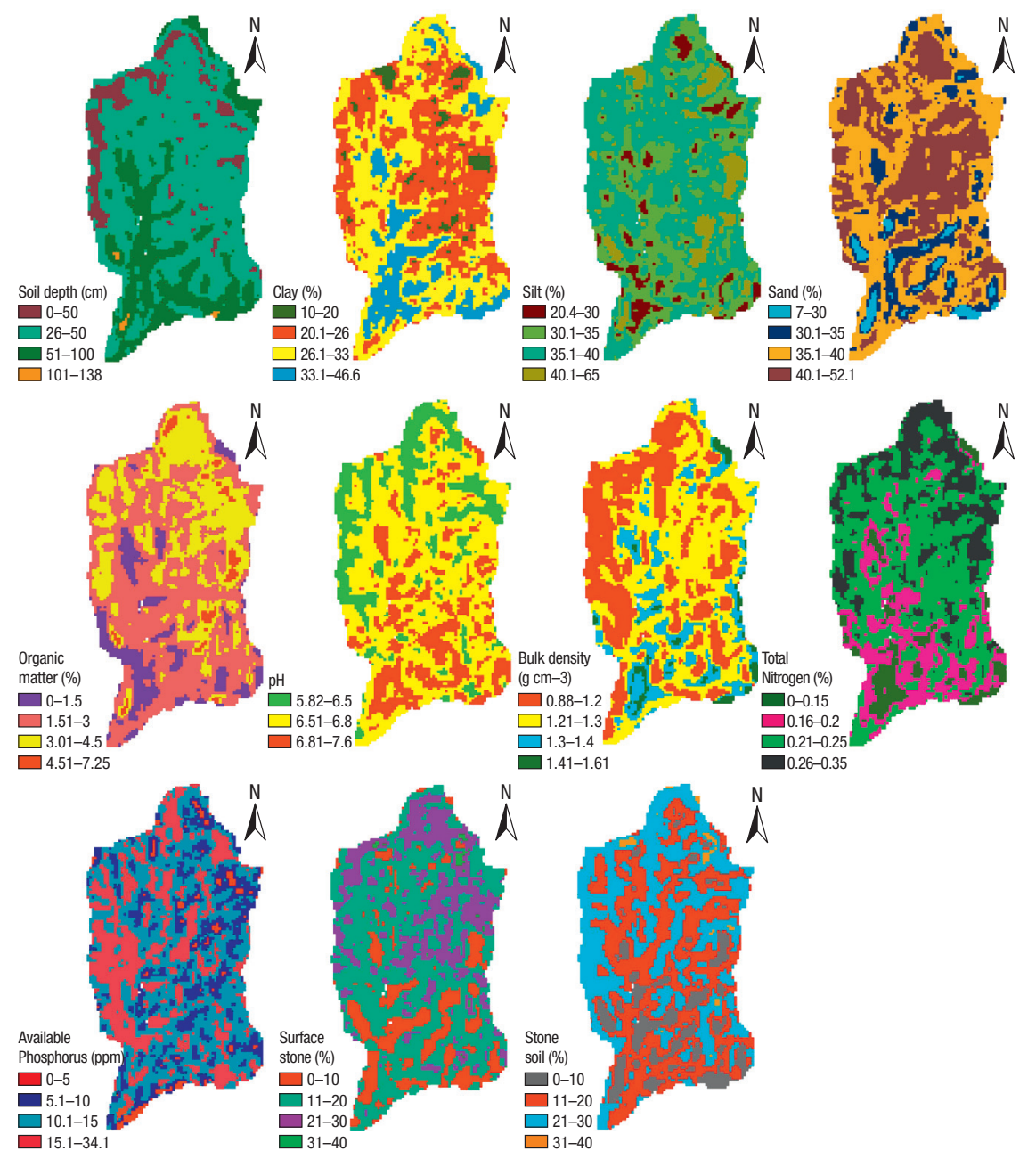

Figure 4.5 Predicted soil attributes of the surface soil using terrain attributes, satellite images and 60 field observations

models for most soil characteristics when compared with previous studies (Ziadat, 2010; Kunkel et al., 2011; Zhang et al., 2012). The results indicated good accuracy even when only sixty observations were used to predict soil attributes. The results indicated that soil attributes were predicted (Figure 4.4 and Figure 4.5) with acceptable accuracy using SRTM 90-m DEM and also provide a visual representation of the spatial distribution of soil attributes. This indicated that soil attributes can be predicted with lower resolution DEMs. These conclusions were similar to those of Thompson et al. (2001) and Wechsler (2006), who concluded that higher resolution DEMs may not be necessary for soil-landscape modelling. 


\section{Conclusions and recommendations}

Both qualitative and quantitative DEM accuracy assessment methods indicated that low resolution DEM (SRTM 90-m) was better than higher resolution DEMs $(30-\mathrm{m})$ for the study area. This indicated that higher resolution DEMs do not necessarily have a better accuracy than lower resolution DEMs for soil-landscape modelling. So it is worth checking the accuracy of the DEMs before selecting them. However, selection of an appropriate resolution will depend on the characteristics of the study area and the nature of the analysis; they will have an impact on the precision of the derived terrain attributes and in turn on the predicted soil attributes.

The soil prediction results indicated that soil attributes were predicted with acceptable accuracy using multiple linear regression models from freely available DEM (90-m resolution) and satellite images. In addition, the prediction model was accurate even when a limited number of observations were used, which is usually the case in data-scarce areas such as Ethiopia. The generated predictions will be very useful for supplying information for specific-purpose modelling activities such as SWAT, especially for a country such as Ethiopia where information on the detailed spatial distribution of soil attributes is very scarce.

\section{Acknowledgement}

This research project was funded by the Austrian Development Agency, the operational unit of the Austrian Development Cooperation, and carried out through collaboration between Amhara Regional Agricultural Research Institute (ARARI), Gondar Agricultural Research Center (GARC) and the International Center for Agricultural Research in the Dry Areas (ICARDA).

\section{References}

Aksoy, E., Ozsoy, G. and Sabri, D.M., 2009. 'Soil mapping approach in GIS using Landsat satellite imagery and DEM data'. African Journal of Agricultural Research, 4(11): 1295-302.

Al-Shamiri, A. and Ziadat, F.M., 2012. 'Soil-landscape modeling and land suitability evaluation: The case of rainwater harvesting in a dry rangeland environment'. International Journal of Applied Earth Observation and Geoinformation, 18: 157-64.

Bouma, J., 2001. 'The role of soil science in the land use negotiation process'. Soil Use and Management, 17: 1-6.

Food and Agriculture Organization (FAO), 2006. 'Guidelines for soil descriptions'. FAO, Rome.

Gao, J., 1997. 'Resolution and accuracy of terrain representation by grid DEMs at a microscale'. International Journal of Geographical Information Science, 11: 199-212.

Gessler, P.E., Moore, I.D., McKenzie, N.J. and Ryan, P.J., 1995. 'Soil-landscape modeling and spatial prediction of soil attributes'. International Journal of Geographical Information Science (special issue: 'Integrating GIS and Environmental Modeling'), 9: 421-32. 
Giasson, E., Clarke, T.R., Junior, I.V.A., Merten, H.G. and Tornquist, G.C., 2006. 'Digital soil mapping using multiple logistic regression on terrain parameters in southern Brazil'. Scientia Agricola, 63: 3.

Kunkel, L.M., Alejandro, N.F., Toni, J.S., McNamara, J.P. and Shawn, G.B., 2011. 'A simplified approach for estimating soil carbon and nitrogen stocks in semi-arid complex terrain'. Geoderma, 165: 1.

Liu, X., Peterson, J. Zhang, Z. and Chandra, S., 2006. 'Improving Soil Salinity Prediction with Resolution DEM Derived for LIDAR Data'. Center for GIS, School of Geography and Environmental Science, Monash University, Australia.

McBratney, A.B., Mendonc Santos, M.L., Minasny, B., 2003. 'On digital soil mapping'. Geoderma, 117: 3-52.

Mermut, A.R. and Eswaran, H., 2001. 'Some major developments in soil science since the mid-1960s'. Geoderma, 100: 403-26.

Moore, I.D., Gessler, P.E. and Nielson, G.A., 1993. 'Soil attribute prediction using terrain analysis'. Soil Science Society of America Journal, 57: 443-52.

Phillips, J.D., 2002. 'Spatial structures and scale in categorical maps'. Geographical and Environmental Modelling, 6: 41-57.

Rossiter, D.G., 2005. 'Digital soil mapping: Towards a multiple-use soil information system'. Santa Fe Bogota, Colombia.

Salehi, M.H., Eghbal, M.K. and Khademi, H., 2003. 'Comparison of soil variability in a detailed and a reconnaissance soil map in central Iran'. Geoderma, 111: 45-56.

Scull, P., Franklin, J. and Chadwick, O.A., 2005. 'The application of decision tree analysis to soil type prediction in a desert landscape'. International Journal on Ecological Modelling and Systems Ecology, 181: 1-15.

Stum, A.K., 2010. 'Random Forests Applied as a Soil Spatial Predictive Model in Arid Utah'. MSc thesis, Utah State University, Utah, UT. Paper 736.

Sumfleth, K. and Duttmann, R., 2008. 'Prediction of soil property distribution in paddy soil landscapes using terrain data and satellite information as indicators'. Ecological Indicators, 8(5): 485-501.

Thompson, J.A., Bell, J.C. and Butler, C.A., 2001. 'Digital elevation model resolution: effects on terrain attribute calculation and quantitative soil-landscape modeling'. Geoderma, 100: 67-89.

Van de Wauw, J., Baert, G., Moeyersons, J., Nyssen, J., De Geyndt, K., Nurhussein, T., Amanuel, Z., Poesen, J. and Deckers, J., 2008. 'Soil-landscape relationships in the basaltdominated highlands of Tigray, Ethiopia'. Catena, 75: 117-27.

Wechsler, S., 2000. 'Effect of DEM Uncertainty on Topographic Parameters, DEM Scale and Terrain Evaluation'. PhD thesis, State University of New York, College of Environmental Science and Forestry, Syracuse, NY.

Wechsler, S., 2006. 'Uncertainties associated with digital elevation models for hydrologic applications: a review'. Hydrology and Earth System Sciences, 3: 2343-84.

Zhang, S., Huang, Y., Shen, C., Ye, H. and Du, Y., 2012. 'Spatial prediction of soil organic matter using terrain indices and categorical variables as auxiliary information'. Geoderma, 171-2: 35-43.

Zhou, Q. and Liu, X., 2004. 'Analysis of errors of derived slope and aspect related to DEM data properties'. Computers \& Geosciences, 30: 369-78.

Ziadat, F., 2007. 'Effect of contour intervals and grid cell size on the accuracy of DEMs and slope derivatives'. Transactions in GIS, 11(1): 67-81.

Ziadat, F.M., 2010. 'Prediction of soil depth from digital terrain data by integrating statistical and visual approaches'. Pedosphere, 20(3): 361-7. 